Original Research Paper

\title{
Evaluation of Fire Effects on Reinforced Concrete Columns Using Finite Element Method
}

\author{
${ }^{1}$ Sajjad Sayyar Roudsari and ${ }^{2}$ Taher M. Abu-Lebdeh \\ ${ }^{1}$ Department of Civil, Architectural and Environmental Engineering, \\ North Carolina A and T State University, Greensboro, NC 27411, USA \\ ${ }^{2}$ Department of Civil, Architectural and Environmental Engineering, \\ North Carolina A\&T State University, Greensboro, NC 27411, USA
}

Article history

Received: 05-05-2019

Revised: 04-06-2019

Accepted: 19-06-2019

Corresponding Author: Sajjad Sayyar Roudsari

Department of Civil,

Architectural and

Environmental Engineering,

North Carolina A and T State

University, Greensboro, NC

27411, USA

Email: taher@ncat.edu

\begin{abstract}
In this paper, four different Reinforced Concrete (RC) columns are analyzed with Finite Element (FE) ABAQUS software and validated experimentally. One of the RC columns, the control specimen, is subjected to only compressive force applied at both ends of the column, while the other three models were loaded under both compressive force and fire load. The temperature is applied to reach up to 600 Celsius Degree for the period of 10,15 and $20 \mathrm{~min}$. The load-displacement diagrams were constructed. Results showed good correlations between experimental and FE analysis. Moreover, results showed reduction in load capacity as duration of fire load increases.
\end{abstract}

Keywords: Finite Element Method, ABAQUS, Reinforced Concrete Column, Fire Loading, Fire Duration

\section{Introduction}

The Reinforced Concrete (RC) column is one of the most important elements of a structure. When the $\mathrm{RC}$ column is subjected to the extreme loading conditons, some negative efects are occurred on the concrete material such as the load capacity performace, durability (Winkler, 1997; Adorni and Venturelli, 2010). The RC columns can transfer the loads to the foundation and due to extreme loading conditions such as fire, the failure occurres (Sakai and Sheikh, 1989) disrupting transfering of loads. Exposing of RC column to fire load will also cause reduction in concrete strength and deformation features (Book et al., 1990). Kodur et al. (2005) conducted experimental tests on reinforced concrete columns under fire loads. He constructed RC columns with circular and square cross-sections with 400 millimeter (diameter, length). Moreover, some of the columns were wrapped with FRP sheets. The fire was applied for about 5 hours. The results showed that FRP could increase the load capacity. Nada et al. (2011) carried out experimental tests on 128 reinforced concrete columns which were divided into two groups. The main difference between the groups was the concrete compressive strength ( 30 and $40 \mathrm{MPa}$ ). The columns were exposed to fire flame and load capacity diagrams were carried out based upon three codes as ACI$318 / 08$, BS-8110/97. Results indicated that by increasing the fire temperature, the crack width increased. Nada et al. (2011) discussed the effect of fire on the RC members. Coile et al. $(2012 ; 2014)$ performed numerical analysis on RC slab and found out the effect of different temperatures on the bending strength of concrete. The Monto Carlo method has also been used to evaluate the RC columns subjected to fire loading condition (Sidibé et al., 2000). Al-Taai et al. (2018) performed finite element simulation by ANSYS software to investigate the effect of fire on reinforced concrete columns. He evaluated the effect of FRP on the load capacity of RC columns. His results indicated that using Carbon Fiber Reinforced Polymer (CFRP) enhanced the ultimate strength range. Jean-Marc and

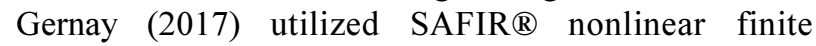
element software to model the structural element under fire conditions. He applied the thermal characteristics like the location of the fire to investigate the behavior of structure. He reported the capabilities of this software in modeling and simulating of structural elements under fire loading conditions. There are many experimental researches regarding the effect of fire on the RC columns (Kodur and Agrawal, 2016; Kodur et al., 2017), but there are few studies on numerical modeling (Bratina et al., 2005). Thus, there is a need for numerical 
investigations to discuss the effect of fire durance in RC columns, numerically.

\section{Finite Element Model}

In this paper, the reinforced concrete columns were modeled using ABAQUS. In order to simulate RC columns under fire loadings, experimental tests are needed. Bikhiet et al. (2014) conducted such experiments. He constructed 15 different $\mathrm{RC}$ columns with the dimension of $15 \times 15 \times 100(\mathrm{~cm})$ or one-third scale. The longitudinal bars diameter were $4 \varnothing 16$ and the stirrups were distributed as $06 @ 10 \mathrm{~cm}$. Figure 1shows the cross-section of RC column. In the experiments, the fire load was applied in addition to compressive force. In fact, the RC colums were exposed to fire, first and then, columns were tested under compressive force by using hydraulic loading machine up to failure. The fire temperature was assigned to be $600^{\circ} \mathrm{C}$, constantly (the experimental procedures is based on ASTM E119 Standard). The concrete compressive in the range of 29.5 to $49 \mathrm{MPa}$. The experimental setup is shown in Fig. 2.

In this study, the analyzed four RC columns are tabulated in Table 1. The concrete compressive strength is $29.5 \mathrm{MPa}$ for all specimens.

The ABAQUS software is used to model the RC columns. The solid part with C3D8R and the truss element (T3D2) a 2-node linear 3-D truss ( $A B A Q U S$ Documentation) were used to model the investigated columns. Further, Concrete Damage Plasticity (CDP) model is employed to compute the required concrete parameters. Figure 3 displays the plastic strain-stress graph of CDP model for $29.5 \mathrm{MPa}$ compressive strength.

The fire affects on the reinfrocements such as transvers longitudinal bars and concrete, respectively. The Equation 1 indicates the yield point of steel bars based on different temprature:

$$
\begin{aligned}
& F_{y}=F_{y 0}\left(1+\frac{T_{c}}{767 \ln \left(\frac{T_{c}}{1750}\right)}\right) 0<T_{c} \leq 600^{\circ} \mathrm{C} \\
& F_{y}=F_{y 0}\left(\frac{108-\frac{T_{c}}{1000}}{T_{c}-440}\right) 600<T_{c} \leq 1000^{\circ} \mathrm{C}
\end{aligned}
$$

$F_{y}$ is steel yield stress in increted temperature, $F_{y 0}$ is the yeild stress in room temperature and $\mathrm{T}_{\mathrm{c}}$ is the applied fire temperature. The initial boundary condition for the concrete is at room temperature $\left(25^{\circ} \mathrm{C}\right)$ which is called Heat Sink. This parameter can be assigned as Surface Film Condition in ABAQUS software. In addition to heat sink, the boundary conditions are divided into two radiation and convection which can be observed at Equation 2 and 3, in order:
Table 1: Sample fire loading (Bikhiet et al., 2014)

\begin{tabular}{lc}
\hline Column ID & Fire period $(\mathrm{min})$ \\
\hline S1 & 0.00 \\
S2 & 10.00 \\
S3 & 15.00 \\
S4 & 20.00 \\
\hline
\end{tabular}

$q_{r}^{n}=\Phi \varepsilon_{t} \sigma T_{c}^{4}$

$q_{h}^{n}=h \Delta T$

In these equations, the heat flux due to convection $\left(q_{h}^{n}\right)$, the heat flux due to radiation $\left(q_{r}^{n}\right)$, configuration factor $(\Phi)$, the emissivity factor, ranged from 0-1.0 $\left(\varepsilon_{t}\right)$, the Stefan-Boltzmann constant taken as $(5.67 \times 10-8$ $\mathrm{W} / \mathrm{m} 2 \mathrm{~K} 4)(\sigma)$, is the absolute temperature of the emitting surface $\left(T_{e}\right) .(\Delta T)$ the temperature difference between the solid surface and fluid in $\left({ }^{\circ} \mathrm{C}\right.$ or $\left.\mathrm{K}\right)$ and $\mathrm{h}$ (the convective heat transfer coefficient in $\left(\mathrm{W} / \mathrm{m}^{2} \mathrm{~K}\right)$, typical vale is $\left.25 \mathrm{~W} / \mathrm{m}^{2} \mathrm{~K}\right)$. Moreover, the initial and boundary conditions are at Equation 4 and 5, respectively:

$T(x, y, z, 0)=T 0(x, y, z, 0)$

$-k \frac{\partial T}{\partial u}=h_{c}\left(T_{s}-T_{f}\right)+h_{c}\left(T_{s}-T_{f}\right)$

$T_{S}$ is the temperature of solid surface; $T_{f}$ is the temperature of fluid, $S$ is the internally generated heat on unit volume per unit time, $h_{c}$ is the heat transfer coefficient of solid surface, $u$ is the direction of heat and $k$ is the conductivity.

The conductivetity of concrete was selected to be 0.0005 (at $0^{\circ} \mathrm{C}$ ) and 0.00114 (at $600^{\circ} \mathrm{C}$ ). Also, the concrete specific heat is considered to be 1000 at $600^{\circ} \mathrm{C}$. The high grade steel is used for the material properties in which the steel's specific heat of 5225 is applied. Meanwhile, the conductivity of steel is considered to be 0.04 (at $0^{\circ} \mathrm{C}$ ) and 0.0518 (at $600^{\circ} \mathrm{C}$ ). It shuld be noted that ASTM E119 Standard is used for fire criteria. Since the experimental tests considered compressvie and fire loads, the herein FEM analysis uses Coupled-TempDisplacement (Transient). This type of alanysis has the capability to apply both fire and earthquake load like laterial or compressive pressure loads.

It should be noted that the Embedded Region is applied to simulate the interaction between steel bars and concrete. The surface film coefition of 0.01 is applied at room temperate degree $\left(25^{\circ} \mathrm{C}\right)$. The displacement control is applied as compressive load on the top and bottom surface of the colum. The Node Distribution Method is employed to apply the load. The fire is loaded as Temperature Type with load factor-time as shown in Fig. 4. 
All models are analyzed under the same displacement $(5 \mathrm{~mm})$ and fire temperature of $600^{\circ} \mathrm{C}$. Moreover, the maximum allowable tempersture change per increment is considered to be 10 Celsius Degree. It should be noted that Prefield temperature is also assigned as room temperature. The RC modeling is displayed in Fig. 5.
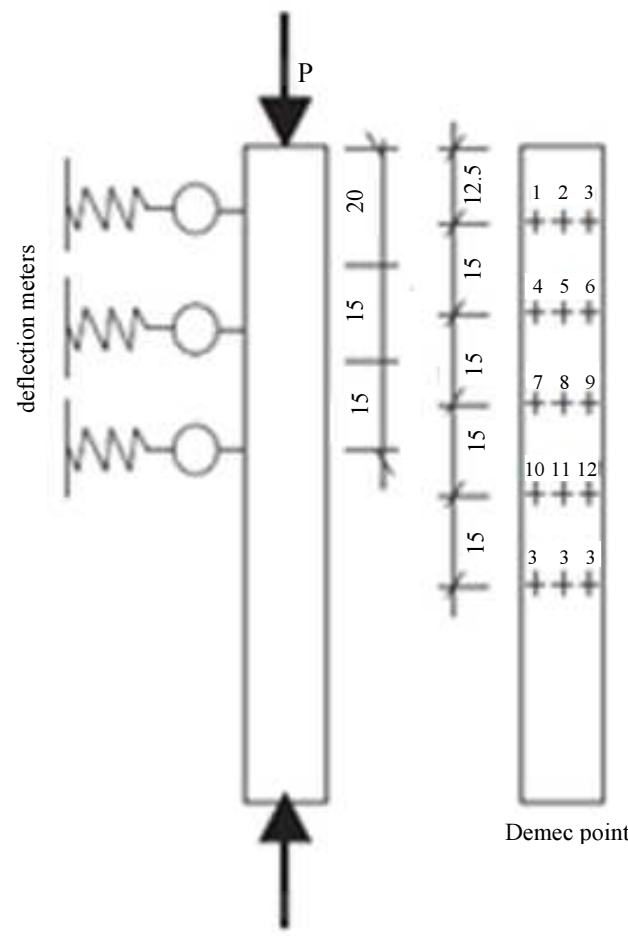

응

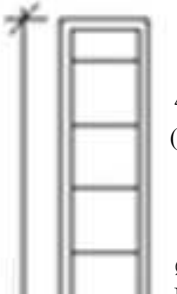

4 Bars diameters

(high grade steel)

$\varnothing 6 \mathrm{~mm}$

Mild steel stirrups

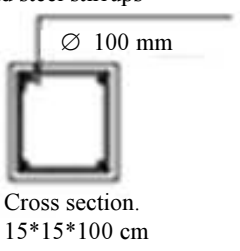

Fig. 1: Cross-section of RC column (Bikhiet et al., 2014)
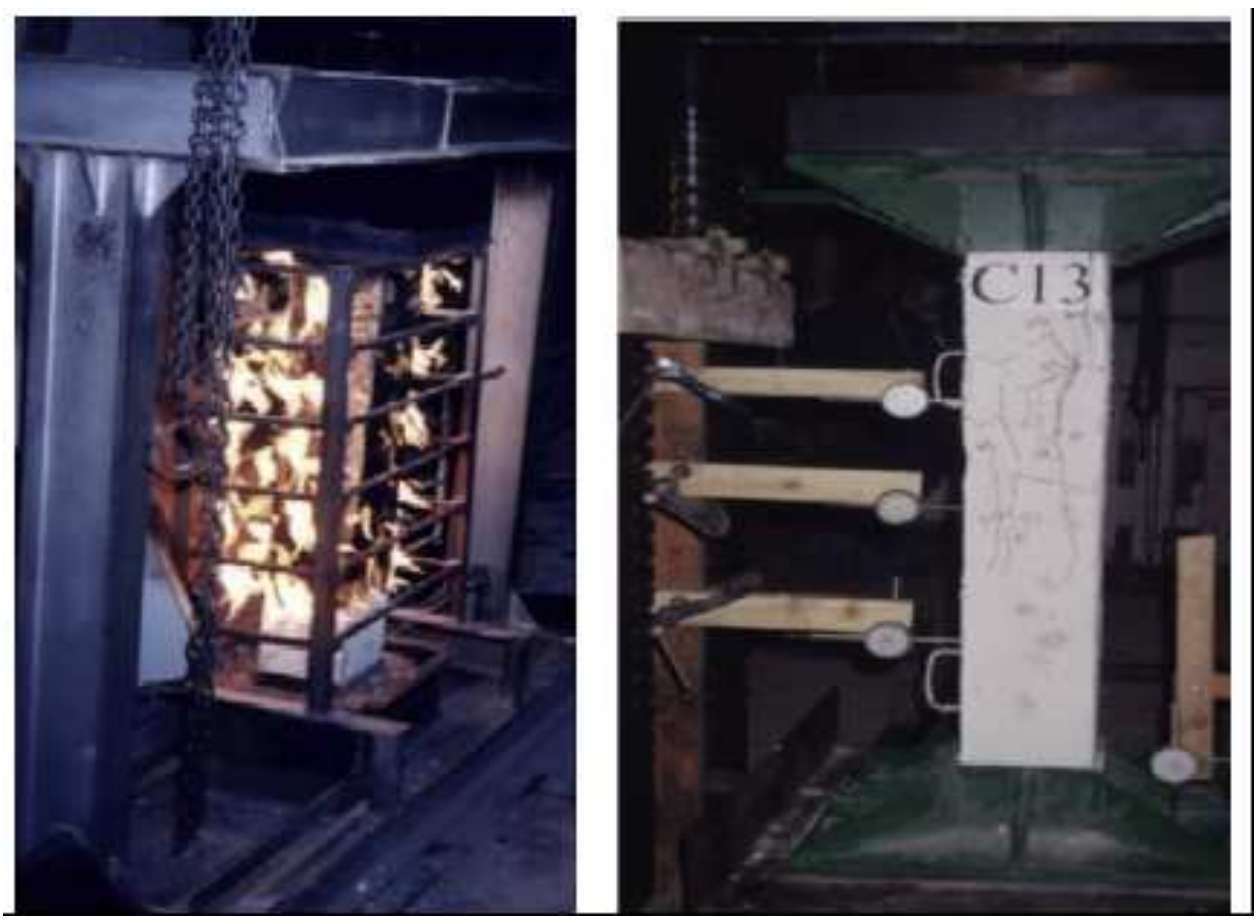

Fig. 2: An ExoMars rover as an exhibit at gasometer oberhausen, Germany 


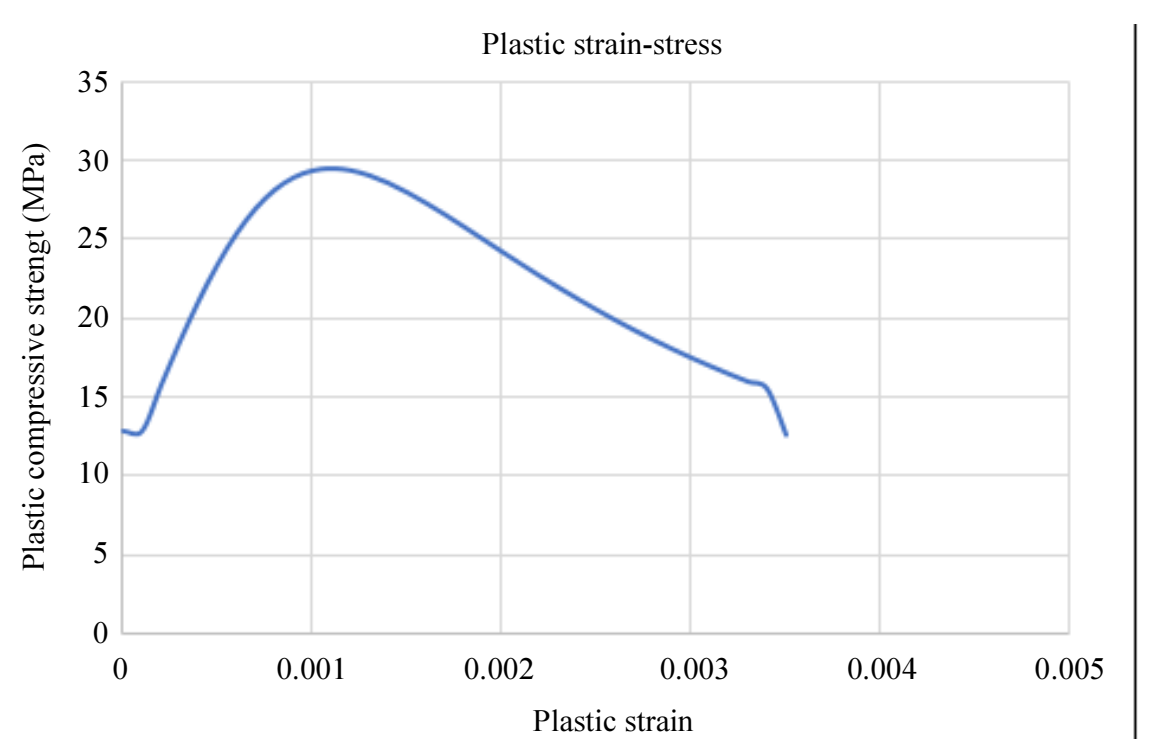

Fig. 3: CDP parameters-compressive side

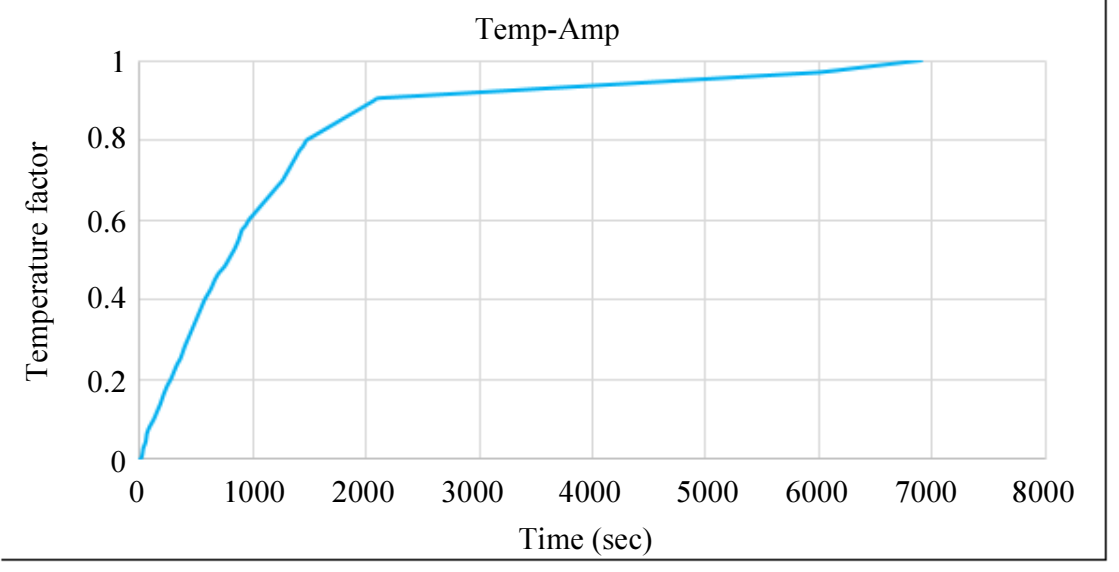

Fig. 4: Temperature-time amplitude (ASTM E119-88, 1990)

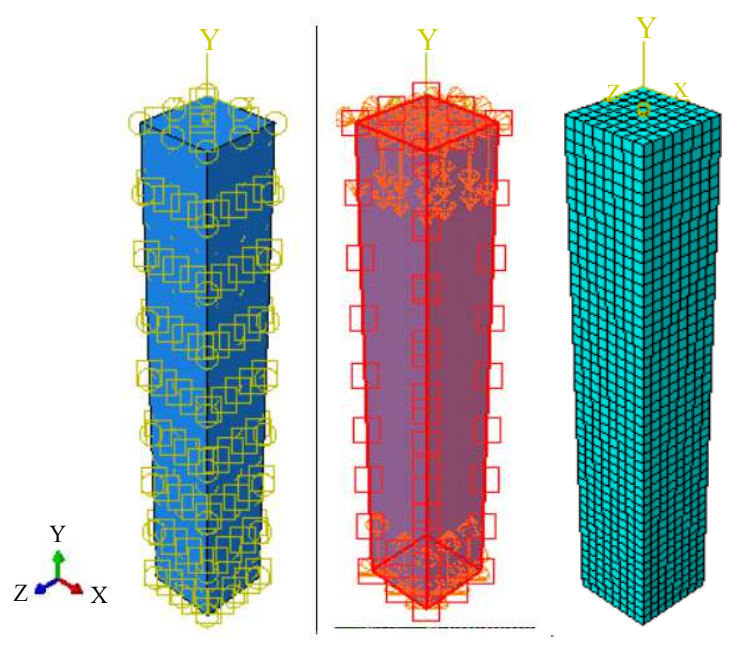

Fig. 5: RC modeling in ABAQUS 


\section{Results and Discussion}

In this section, the results of the finite element analysis are explained. Based on Table 1, S1 has no fire load, S2, S3 and S4 are loaded in the period of 10, 15 and 20 minutes. The load displacement validations are shown in Figs. 6 to 9. Figure 6 showes the comaprison between the FEM and experimental results for S1. The difference in the maximum load capacity and displacement is about $12 \%$ and $4 \%$, respectively. The validation error for S2 (Fig. 7) is $-5.5 \%$ for displacement and less than $1 \%$ for maximum load capacity. Figure 8 also shows the difference of load capacity and displacement are about $3 \%$ and $-6 \%$. In Fig. 9, $-2 \%$ and $8.5 \%$ are the validation error for maximum load capacity and displacement, respectively. It should be note that, the minus sign indicates that the maximum FEM value is less than experimental result.

Figure 10 shows the Plastic Equivalent Strain (PEEQ). As it can be seen, the distribution of plastic strain increases as the time period of fire load increased. Examining S4 (RC column as fired for 20 minutes) shows that most elements are failed due to long period. In other words, by applying the fire load (such as in S2), the crack tips are began or initiated, while increasign the time (as in S3 and S4) the cracks will propagate.

The reduction in the load capacity obtained by the finite element analysis is shown in Figure 11. In this figure, the models with fire loads are compared with model without fire (S1). As illustrated, the longer the period of fire the higher reduction in load capacity occurs. In this regard, S4 (20 min fire load) has higher reduction in load capacity (about 30\%).

On the other hand, due to the behavior of RC columns under fire loading condition, finding stiffness is eccential (Equation 6). In this equation, $V_{y}$ and $\Delta_{y}$ are the load and displacement at the yield point:

$E=\frac{\Delta_{y}}{\Delta_{y}}$

The stiffness of experimental and finite element results is shown in Fig. 12. As it can be seen, the stiffness is reduced by increasing the time of applying fire load. Comparing experimental result for S2 (10minutes fire load), S3 (15-minutes fire load) and S4 (20-minutes fire load) with S1 (no fire) shows $17.3 \%$, $24.8 \%$ and $34.6 \%$ reduction of stiffness. The stiffness reduction for finite element results is $16.6 \%, 25.7 \%$ and $34.9 \%$ for S2, S3 and S4 in comparison with S1. Moreover, contrasting the experimental with finite element results indicates that the stiffness of experimental values are less than simulation ones. The reason of this issue is due to the loading condition. In fact, looking at Figs. 6 to 9 illustrates that, the loaddisplacement of experimental diagrams have a smooth slop at the first $25 \%$ of maximum load. This issue is because of the rate of loading and the time between initial and actual pressure in the laborator.

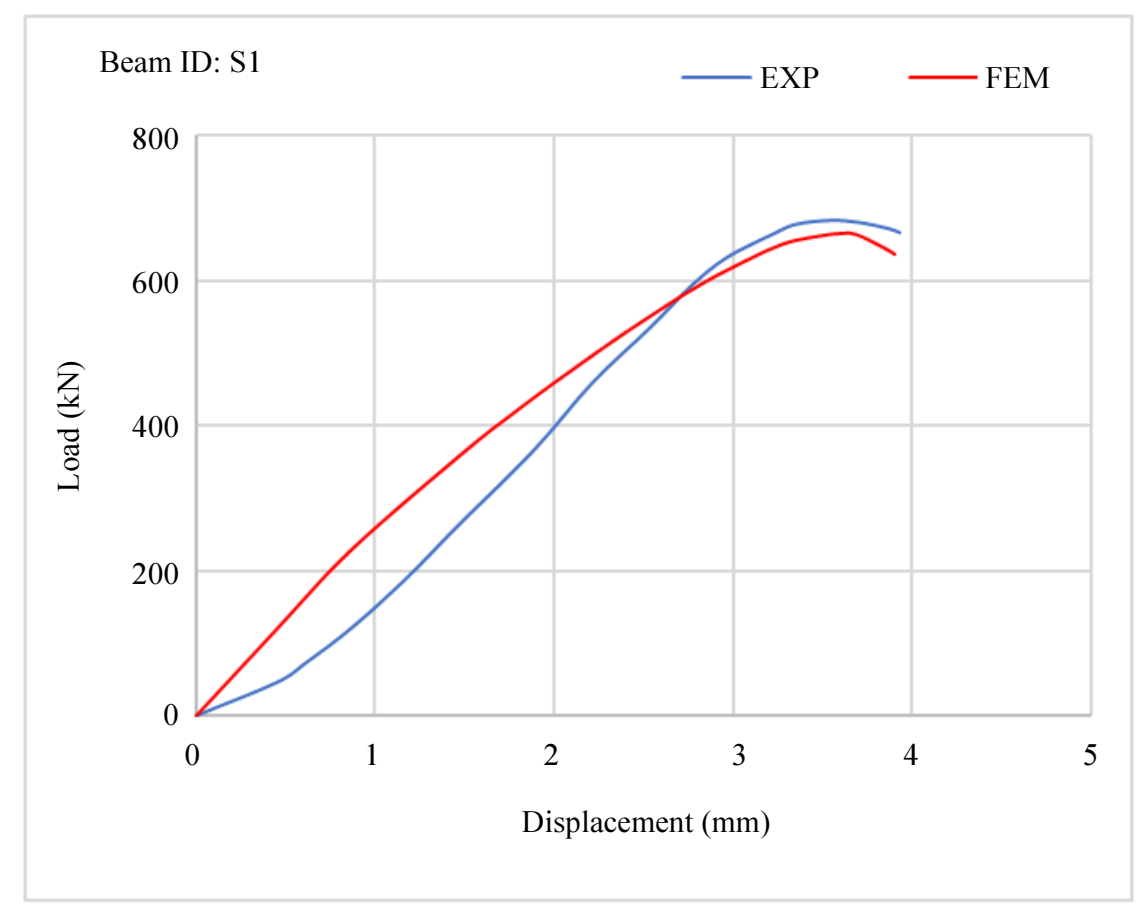

Fig. 6: Load-Displacement: S1 - Without Fire (control) 


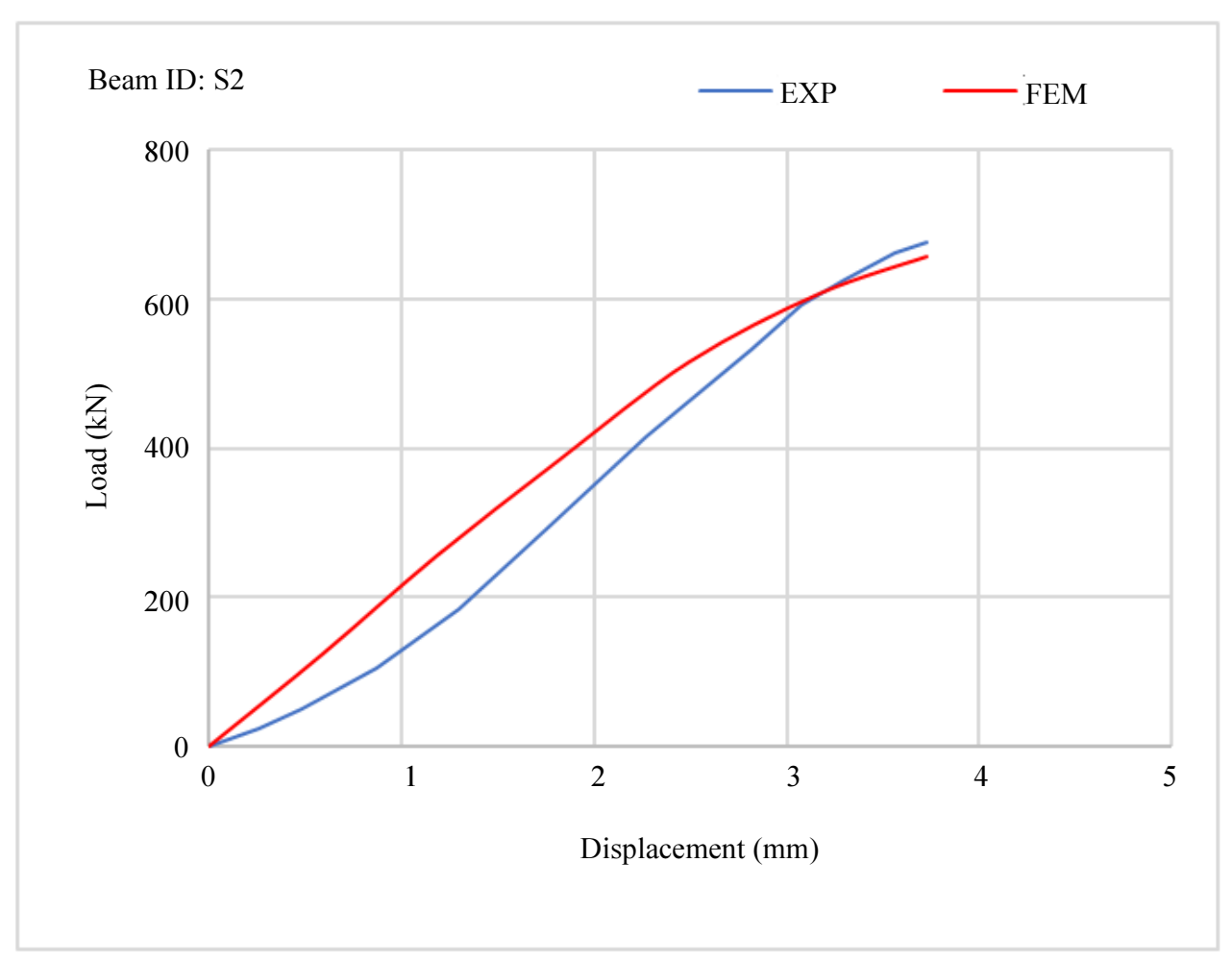

Fig. 7: Load-Displacement: S2 (10 min Fire)

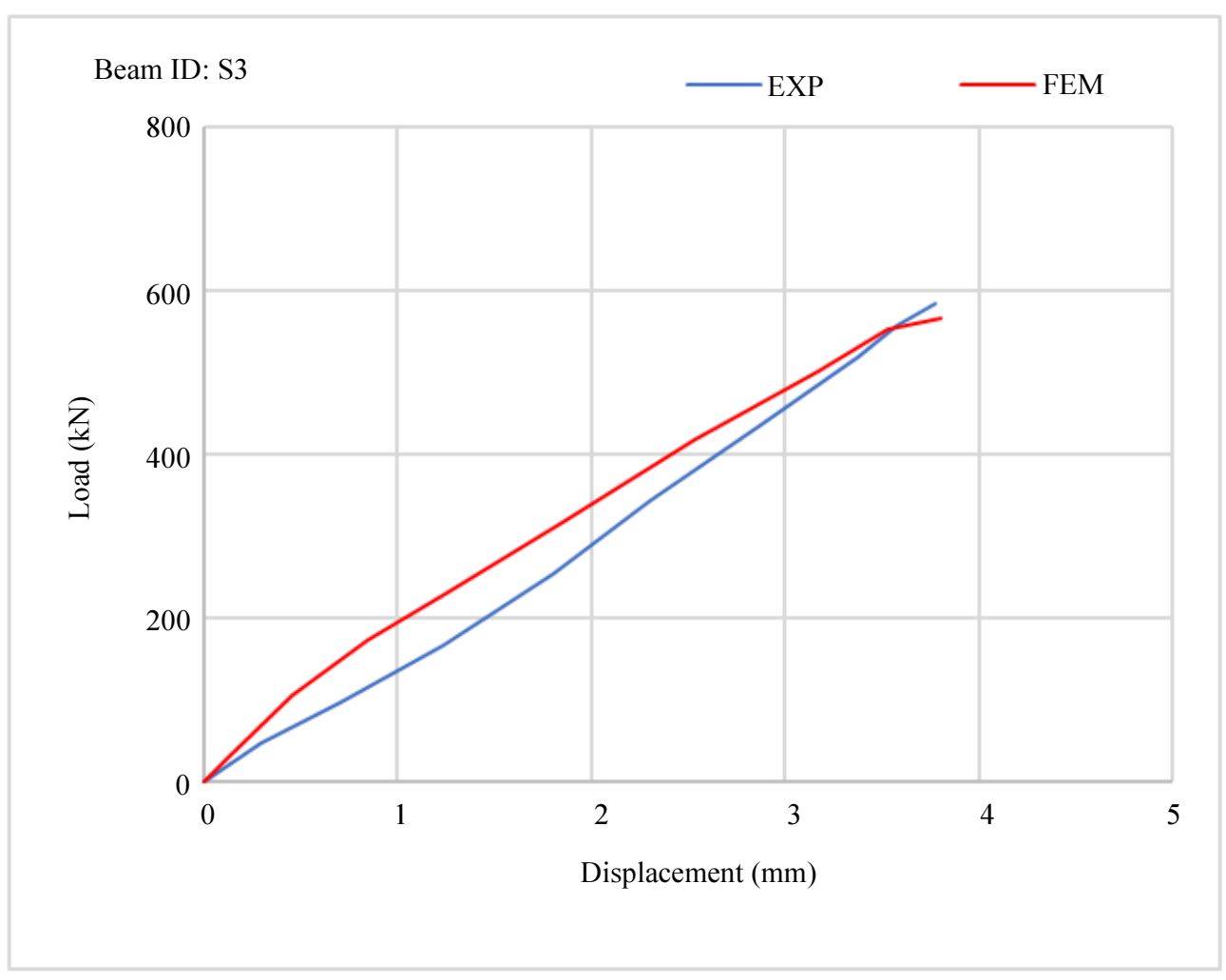

Fig. 8: Load-Displacement: S3 (15 minutes Fire) 


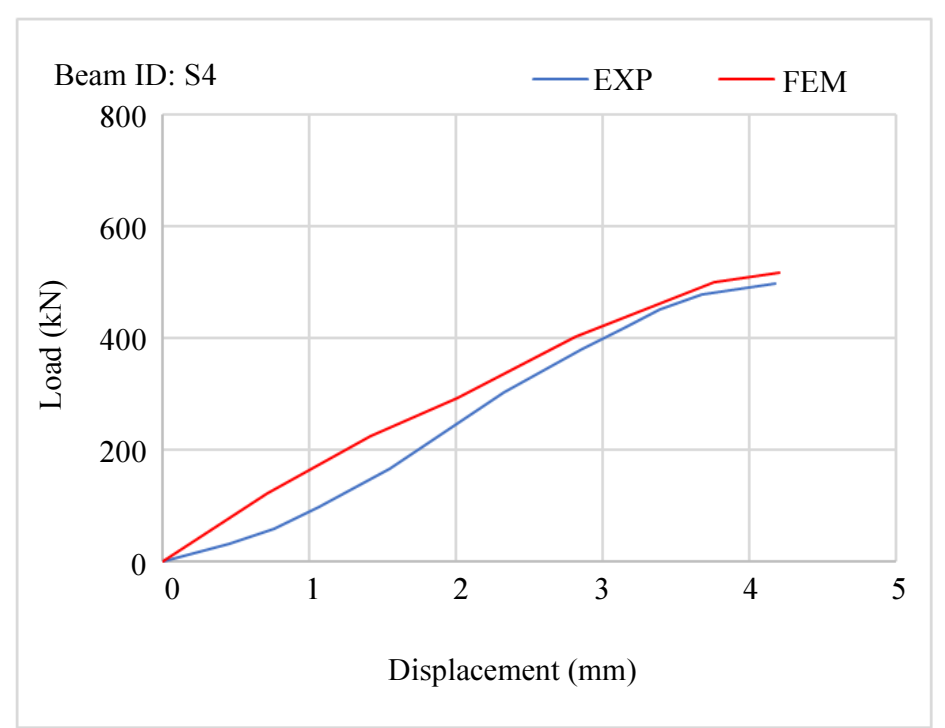

Fig. 9: Load-Displacement: S4 - 20 min Fire

S1

\begin{tabular}{|c|c|}
\hline $\begin{array}{l}\text { PEEQ } \\
\text { (Avg: } 75 \% \text { ) }\end{array}$ & $\begin{array}{l}\text { PEEQ } \\
\text { (Avg: } 75 \% \text { ) }\end{array}$ \\
\hline$T+8.427 \mathrm{e}-02$ & $+4.449 \mathrm{e}-03$ \\
\hline$-+7.725 \mathrm{e}-02$ & $-+4.079 \mathrm{e}-03$ \\
\hline$-+7.023 \mathrm{e}-02$ & $-+3.708 \mathrm{e}-03$ \\
\hline$+6.320 \mathrm{e}-02$ & $-+3.337 \mathrm{e}-03$ \\
\hline$+5.618 \mathrm{e}-02$ & $-+2.966 \mathrm{e}-03$ \\
\hline$-+4.916 \mathrm{e}-02$ & $-+2.595 \mathrm{e}-03$ \\
\hline$-+4.214 \mathrm{e}-02$ & $-+2.225 \mathrm{e}-03$ \\
\hline$-+3.511 \mathrm{e}-02$ & $-+1.854 \mathrm{e}-03$ \\
\hline$-+2.809 \mathrm{e}-02$ & $-+1.483 e-03$ \\
\hline$-+2.107 \mathrm{e}-02$ & $-+1.112 \mathrm{e}-03$ \\
\hline$-+1.405 \mathrm{e}-02$ & $-+7.416 \mathrm{e}-04$ \\
\hline$-+7.023 \mathrm{e}-03$ & $-+3.708 \mathrm{e}-04$ \\
\hline$L_{+0.000 \mathrm{e}+00}$ & $-+0.000 \mathrm{e}+00$ \\
\hline
\end{tabular}
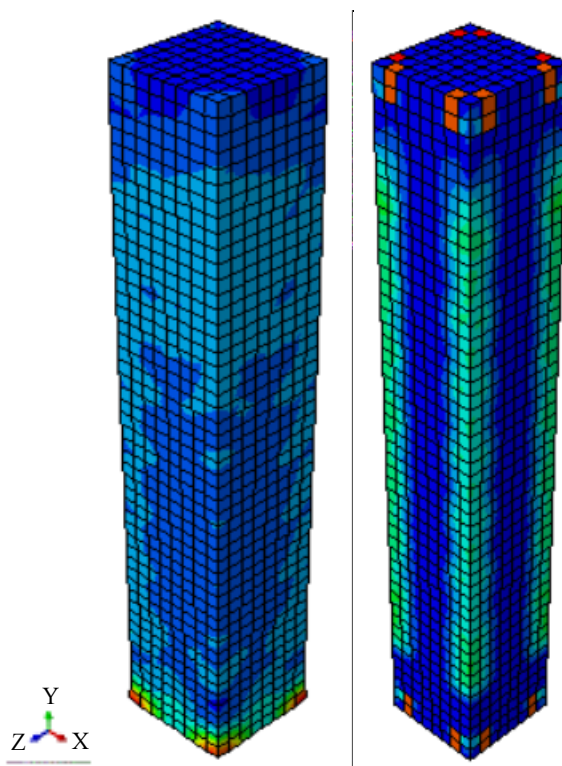

S3

\begin{tabular}{|c|}
\hline $\begin{array}{l}\text { PEEQ } \\
\begin{aligned} \text { (Avg: } & 75 \%) \\
& +1.002 \mathrm{e}-02 \\
& +9.184 \mathrm{e}-03 \\
& +8.349 \mathrm{e}-03 \\
& +7.514 \mathrm{e}-03 \\
& +6.680 \mathrm{e}-03 \\
& +6.03 \\
& +5.845 \mathrm{e}-03 \\
& +5.010 \mathrm{e}-03 \\
- & +4.175 \mathrm{e}-03 \\
& +3.340 \mathrm{e}-03 \\
& +2.505 \mathrm{e}-03 \\
& +1.670 \mathrm{e}-03 \\
& +8.349 \mathrm{e}-04 \\
& +0.000 \mathrm{e}+00\end{aligned}\end{array}$ \\
\hline
\end{tabular}

PEEQ

(Avg: $75 \%)$

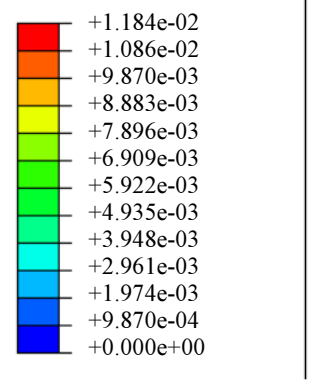

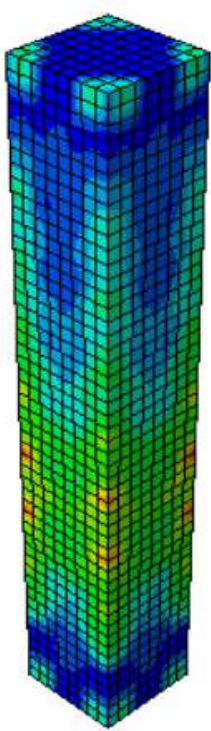

Fig. 10: Equivalent Plastic Strain 


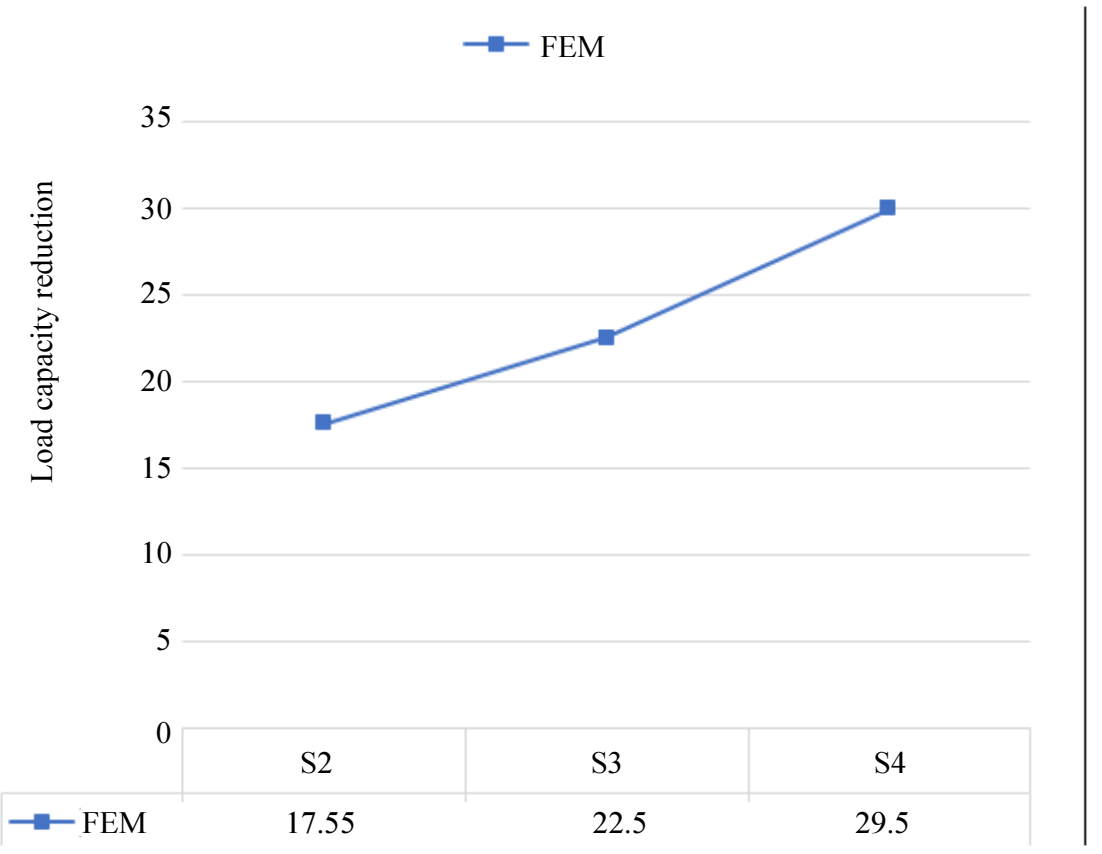

Fig. 11: Reduction in load Capacity due to fire

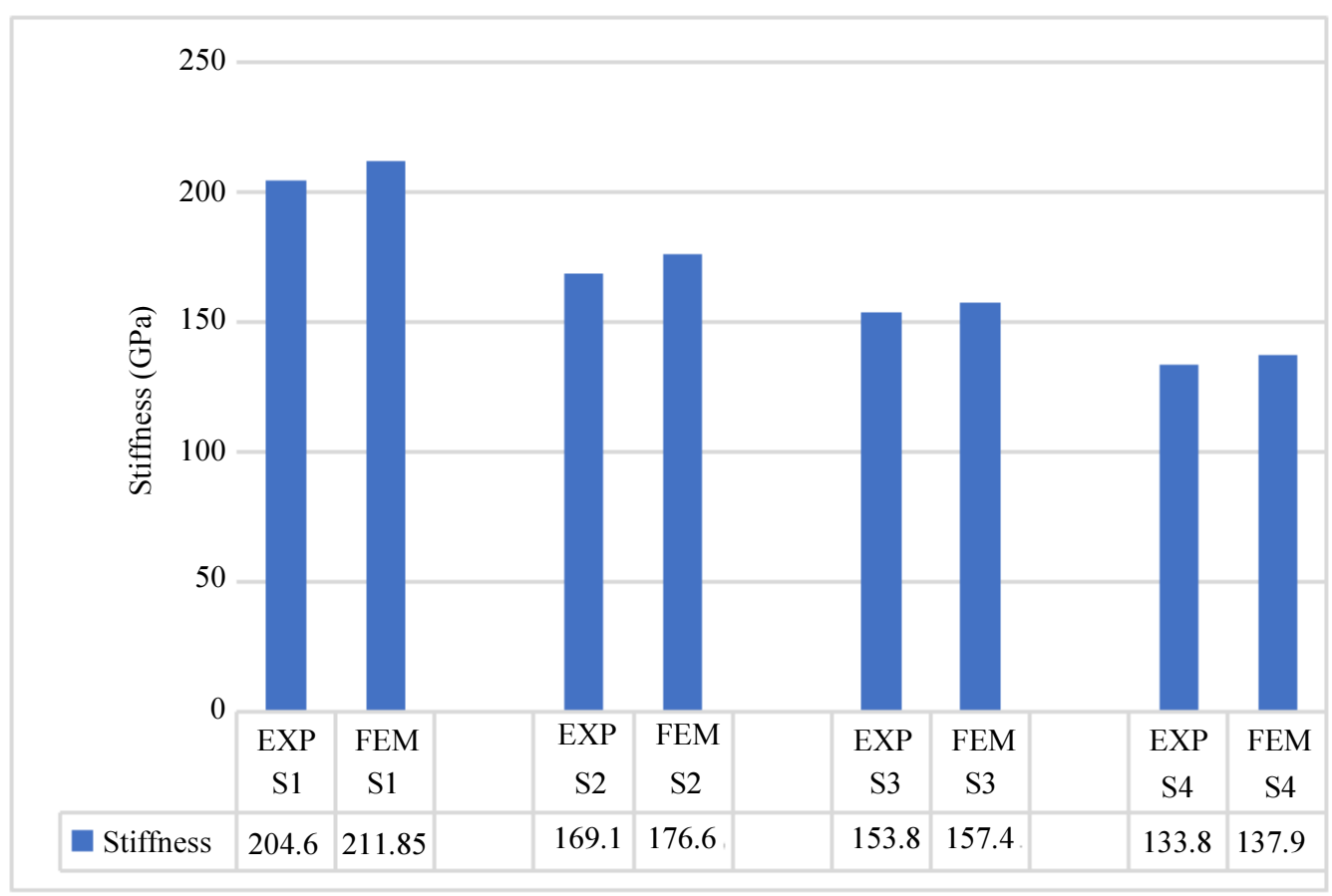

Fig. 12: Stiffness at different fire periods

\section{Conclusion}

This work focused on the peroformance of reinforced concrete columns subjected to different fire load duration. Based on the FEM analysis, the results are as follows:
- Using ABAQUS software can validate and predict the experimental tests

- The longer fire period will reduce load capacity

- The difference of load capacity reduction between 10 and 20 min is more than $12 \%$ 
- The PEEQ visual distribution on RC columns shows that increasing the time of fire load causes the concrete to fail

- Increasing the time of fire load causes more reduction of stiffness

- The finite element stiffness is a bit more than experimental results due to actual loading conditions in the lab

\section{Acknowledgment}

The work was appreciated by Associate Professor Aniello Riccio Seconda Universita' Degli Studi Di NapolI Italy, Dr. (Ms.) Shweta Agarwala Senior Research Scientist at Singapore Center for 3D Printing Nanyang Technological University Singapore, whom we thanks and in this way.

\section{Author's Contributions}

Sajjad Sayyar Roudsari: Provided the research topic, performed modeling with ABAQUS software and data analysis. Also, participated in writing the manuscript.

Taher Abu- Lebdeh: Guided the research development, finite element plan and data analysis. Also, participated in writing the manuscript.

\section{Ethics}

This article is an original research paper. There are no ethical issues that may arise after the publication of this manuscript.

\section{References}

Adorni, E. and G. Venturelli, 2010. Mortars and stones of the damascus citadel (Syria). Int. J. Architectural Heritage, 4: 337-50. DOI: $10.1080 / 15583050903121851$

Al-Taai, A.A.S., S.A. Hassan and L.F. Hussein, 2018. Finite element analysis of corner strengthening of CFRP-confined concrete column. Proceedings of the IOP Conference Series: Materials Science and Engineering, (MSE' 18), Tyrkey.

ASTM E119-88, 1990. Standard methods of fire test on building construction and materials. Philadelphia.

Bikhiet, M., F. Nasser El-Shafey and M.H. El-Hashimy, 2014. Behavior of reinforced concrete short columns exposed to fire. Alexandria Eng. J., 53: 643-653. DOI: 10.1016/j.aej.2014.03.011

Book, N., A.H., S.M. Mirza and T.T. Lie, 1990. Response of direct models of reinforced concrete columns subjected to fire. Aci. Struct. J., 87: 3313-325.
Coile, R.V.., R. Caspeele and L. Taerwe, 2012. Quantifying the structural safety of concrete slabs subjected to the ISO 834 standard fire curve using full-probabilistic FEM. Proceedings of the 10th International Probabilistic Workshop, Nov. 15-16, Stuttgart.

Coile, R.V.., R. Caspeele and L. Taerwe, 2014. The Mixed Lognormal Distribution for a More Precise Assessment of the Reliability of Concrete Slabs Exposed to Fire. Proceedings of the Safety, Reliability and Risk Analysis: Beyond the HorizonSteenbergen, (BHS' 14), Taylor Francis London.

Jean-Marc, F. and T. Gernay, 2017. Modeling structures in fire with safir ${ }^{\circledR}$ : Theoretical background and capabilities. J. Struct. Fire. Eng., 8: 300-323. DOI: 10.1108/JSFE-07-2016-0010

Kodur, V.R.K., L.A. Bisby, M.F. Green and E. Chowdhury, 2005. Fire endurance experiments on FRP strengthened reinforced concrete columns, National Research Council of Canada, Institute for Research in Construction, Research Report No.185, 41-41.

Kodur, V.K.R. and A. Agrawal, 2016. An approach for evaluating residual capacity of reinforced concrete beams exposed to fire. Eng. Struct., 110: 293-306. DOI: 10.1016/j.engstruct.2015.11.047

Kodur, V., D. Hibner and A. Agrawal, 2017. Residual response of reinforced concrete columns exposed to design fires. Proceedings of the 6th International Workshop on Performance, Protection and Strengthening of Structures under Extreme Loading, PROTECT2017, Dec. 11-12, Guangzhou (Canton), China.

Nada, M.F., S.M. Essa and M.K. Mohammed, 2011. Behaviour of fire exposed reinforced concrete columns. J. Eng., 53: 643-653. DOI.org/10.1016/j.aej.2014.03.011

Sakai, K. and S.A. Sheikh, 1989. What do we know about confinement in reinforced concrete columns. Aci. Struct. J., 86: 92-207.

Bratina, S., C. Bojan, M. Saje and I. Planinc, 2005. Numerical modelling of behaviour of reinforced concrete columns in fire and comparison with Eurocode 2. Int. J. Solids Struct., 42: 5715-5733 DOI.org/10.1016/j.ijsolstr.2005.03.015

Sidibé, K.F., M. Duprat and P.B. Bourret, 2000. Fire safety of reinforced concrete columns. Aci. Struct. J., 97: 642-647.

Winkler, E.M., 1997. Stone in Architecture: Properties, Durability. 4th Edn., Springer Science and Business Media, Berlin Heidelberg, ISBN-10: 3642144756 , pp: 552. 